Research Article

\title{
Evolution Characteristics of a High-Level Asymmetric Fracture-Seepage Community and Precise Coalbed Methane Drainage Technology during Mining of Outburst-Prone Coal Seam Groups
}

\author{
Hongbing Wang, ${ }^{1}$ Zhiheng Cheng $\mathbb{D}^{2},{ }^{2}$ Tie Li, ${ }^{1}$ Liang Chen $\mathbb{D}^{2},{ }^{2}$ Quanle Zou, ${ }^{3}$ Shengli Yang, \\ and Jialin $\mathrm{Cao}^{2}$ \\ ${ }^{1}$ School of Civil and Resource Engineering, State Key Laboratory of High-efficiency Mining and Safety of Metal Mine, \\ Ministry of Education, University of Science and Technology Beijing, Beijing, China \\ ${ }^{2}$ School of Safety Engineering, North China Institute of Science and Technology, Beijing 101601, China \\ ${ }^{3}$ School of Resources and Safety Engineering, Chongqing University, Chongqing 400044, China \\ ${ }^{4}$ Faculty of Resource and Safety Engineering, China University of Mining \& Technology (Beijing), Beijing, China
}

Correspondence should be addressed to Zhiheng Cheng; chengzhiheng21@vip.qq.com and Liang Chen; sezichan@126.com

Received 29 January 2021; Revised 26 February 2021; Accepted 8 March 2021; Published 9 April 2021

Academic Editor: Gong-Da Wang

Copyright (c) 2021 Hongbing Wang et al. This is an open access article distributed under the Creative Commons Attribution License, which permits unrestricted use, distribution, and reproduction in any medium, provided the original work is properly cited.

\footnotetext{
The aim of this study is to explore the coupling relationship between fractures in overlying strata and gas seepage fields for pressure relief during mining of outburst-prone coal seam groups and to quantitatively characterize the distribution characteristics of favorable areas for coalbed methane (CBM) drainage in mining-induced fractures of overlying strata. For these purposes, by taking Shaqu No. 1 Coal Mine (Lvliang City, Shanxi Province, China) as a research object, this research studied migration and caving characteristics of overlying strata by combining physical similar material simulation, numerical simulation, and field measurement. Moreover, this study analyzed spatial distribution patterns of mining-induced fractures in overlaying strata, quantitatively characterized distribution parameters of asymmetric-oblique-quadrilateral fracture development zones in overlying strata, and precisely divided areas favorable for CBM drainage. On this basis, evolution laws of an asymmetric fractureseepage community in overlying strata in outburst-prone coal seam groups were obtained, thus optimizing design parameters for directional drilling in the fracture zone in overlying strata. The research results demonstrate that, due to mining-induced influences, strata present different migration and rupture patterns along rupture lines on both sides. Because of different rupture angles $\alpha$ and $\beta$, mining-induced fractures in overlying strata are distributed as an asymmetric-oblique-quadrilateral fracture development body in space. Furthermore, based on the coupling relationship between fracture development states and pressurerelief gas seepage in the fracture development zone in overlying strata of the 4305 rear working face in the mine, this research obtained rupture angles $\alpha \in[74,90)$ and $\beta \in(70,82]$ on both sides of the fracture development zone. Moreover, the intervals favorable for CBM drainage for pressure relief on both sides of the fracture development zone in overlying strata of 4305 rear working face in the mine were separately determined as $x_{a j} \leq 22.68 \mathrm{~m}$ and $24 m \leq x_{\beta j} \leq 37.8 \mathrm{~m}$. If the gas drainage system is designed in this zone, it is of great significance to precise and efficient pressure-relief CBM drainage in the fracture zone and ensure production safety in the mining space.
} 


\section{Introduction}

As coal resources are continuously mined in deep parts of mines in China, deep coal mining has gradually become normal in resource development [1-3]. In the mining of coal resources in deep parts, the occurrence characteristics of high stress, gas pressure, gas content, and low permeability of coal seams become increasingly prominent. Moreover, gas pressure and content in outburst-prone coal seam groups rise, so that gas control in coal seams becomes more difficult [4-7]. This is contrary to the current high-efficient and fully mechanized mining degree and gas always restricts the safe and efficient mining of coal resources. To pertinently prevent and control gas disasters and improve fully mechanized mining efficiency in coal mines, it is necessary to further explore the formation mechanisms and distribution characteristics of fracture fields under mining-induced conditions of coal seam groups. In addition, the space-time transformation for caving of coal-bearing strata and fracture evolution should also be clarified to determine the laws of mining-induced pressure-relief gas seepage. This provides theoretical support for precise prevention and control of gas in outburst-prone coal seam groups.

The technology of simultaneous extraction of coal and gas in outburst-prone coal seam groups is the main means for realizing coal resource exploitation and efficient drainage and utilization of coalbed methane (CBM) resources in such coal seam groups. Moreover, it is also one of the green mining technologies advocated in the present society [8-12]. In the mining of coal seam groups, due to different rock mass properties, roof thicknesses, and interactions between strata, the structures of overlying strata have diverse rupture patterns under influence of mining-induced disturbance. Based on this, many scholars have carried out a lot of studies on mininginduced rupture structures and migration laws of overlying strata [13-16]. They have successively proposed theoretical models including cantilever beam hypothesis, hinged-rock hypothesis, theory of key strata, and transferring rock beams. Moreover, they put forward concepts of three areas (a coal wall support area, a separation area, and a recompression area) in the horizontal direction and three zones (a caving zone, a fracture zone, and a bending and subsidence zone) in the vertical direction based on movement laws of overlying strata after mining coal mass [17]. The mining-induced fractures in overlying strata are channels for gas diffusion, seepage, and migration for pressure relief [18]. Therefore, by studying characteristics of rupture patterns of structures of overlying strata, one can accurately grasp temporal-spatial evolution laws of mining-induced fractures in overlying strata and precisely divide areas favorable for CBM drainage. This is the key to ensuring safe and efficient pressure-relief CBM drainage in overlying strata and is of great significance to safety production and practice of outburst-prone coal seam groups. At present, methods, such as theoretical analysis, locale observation, laboratory similar material simulation, and numerical simulation, have been mostly used in the research on the temporal-spatial evolution laws of mining-induced fractures in overlying strata. For example, based on fractal theory, evolution characteristics of mining-induced fractures in overlying strata before and after mining were studied [19]. Through physical simulation and field measurement, the distribution zones of bed-separation fractures and vertical fractures in a wedge-shape in overlying strata were studied [20]. Based on field measurement and numerical simulation, it is found that a high-level annular fracture body exists in coal seam groups [21]. In addition, by utilizing the laboratory test method, the path control effects of CBM migration characteristics in coal reservoirs were studied, and mechanisms of CBM migration in coal reservoirs were analyzed and discussed [22]. Through similar material simulation methods, it is found that evolution of failure modes in double areas in overlying strata mainly includes four stages, that is, preparation, formation, transformation, and stabilization; moreover, fractures in the zone of overlying strata of the working face were mainly composed of inclined and horizontal fractures [23]. Based on the numerical simulation method, the changes of the average bulking factor of the remnant fractured rock mass were researched. Furthermore, a spatial evolution model for mining and the functional relationship between stress recovery in rock mass caved in a goaf and ground subsidence were established [24]. BBM-DEM fine simulation method is adopted to truly reflect the process of overlying strata fracture and dynamic instability and fracture evolution law [25].

In conclusion, the above research results mainly focus on rupture patterns of structures of overlying strata and evolution and distribution characteristics of mining-induced fractures. However, the quantitative analysis of areas favorable for CBM drainage in mining-induced fractures of overlying strata and the relationship between fracture fields in overlying strata and pressure-relief gas seepage fields remain insufficiently studied, which directly determines the reasonable layout of high-level boreholes and CBM drainage effects. Furthermore, owing to Shaqu No. 1 Coal Mine (Lvliang City, Shanxi Province, China) belongs to a typical mining mine with short distance outburst-prone coal seam groups the poor CBM drainage performance in the fracture zone is easy to cause CBM to go beyond the limit at the working face, thus restricting coal production capacity. On this basis, the author takes Shaqu No.1 Coal Mine as the research object, adopts the method of physical similar material simulation, numerical simulation, and field measurement to study the temporal and spatial evolution law of mining fissures in overburden rock of outburst coal seam group, then precisely divides the favorable areas for CBM drainage, and optimizes the design parameters of directional drilling in overlying strata fracture zone, so as to realize accurate gas drainage for pressure relief of mining-induced fractures.

\section{Mining Conditions of the Working Face}

Shaqu No.1 Coal Mine, subordinating to Huajin Coking Coal Co., Ltd., is located in the west of the middle section of Lvliang Mountains and the middle part of Hedong Coalfield. The minefield is roughly in an NW-SE arc. A total of eight coal seams are approved for mining in the whole minefield, in which $2 \#, 3 \#, 4 \#(3+4 \#)$, and $5 \#$ coal seams are mainly mined. The minimum distance between coal seams is $5.61 \mathrm{~m}$, 
and gas emission from a single well is as high as $113 \mathrm{~m}^{3} / \mathrm{min}$, so it is a typical mine with closely spaced outburst-prone coal seam groups. Furthermore, the average CBM content of $3 \#$ and $4 \#$ coal seams is $11.06 \mathrm{~m}^{3} / t$ and that of $5 \#$ coal seam is $11.16 \mathrm{~m}^{3} / t$. In addition, the permeability coefficient of $3 \#$ and 4\# coal seams ranges from 3.52 to $3.70 \mathrm{~m}^{2} / \mathrm{MPa}^{2} \cdot \mathrm{d}$, while that of $5 \#$ coal seam is in the range of $1.99-2.23 \mathrm{~m}^{2} / \mathrm{MPa}^{2} \cdot \mathrm{d}$. Therefore, the coal seams in the coal mine are characterized by high CBM content and low permeability.

The 4305 rear working face is located in No. 3 mining area of $4 \#$ coal seam, with the front goaf of 4305 working face and 5305 working face in the west and 4306 goaf in the north, $40 \mathrm{~m}$ away from the mine boundary in the east and undeveloped zone in the south. The working face with a strike length of $174 \mathrm{~m}$ and dip length of $396 \mathrm{~m}$ has a dip angle of the coal seam of $8^{\circ}$. The coal seam showed stable occurrence and thickness of $3.9-4.5 \mathrm{~m}$, with an average of $4.4 \mathrm{~m}$ (Figure 1).

\section{Caving Characteristics of Surrounding Rock of the Working Face}

3.1. Physical Simulation of Caving Characteristics of Surrounding Rock of the Working Face. Due to different degrees of mining-induced influences, rupture characteristics of overlying strata are also different. To analyze temporalspatial laws of mining-induced fracture fields in overlying strata under different mining intensities and thus to precisely master reasonable distribution of potential CBM enrichment zones in a fracture body, the method of physical similar material simulation was used.

According to geological conditions for mining the 4305 rear working face in Shaqu No. 1 Coal Mine, a model of similar simulation test of plane stress was built, as shown in Figure 2. The geometric dimensions of the model frame were $1,800 \mathrm{~mm} \times 160 \mathrm{~mm} \times 1,500 \mathrm{~mm} \quad$ (length $\times$ width $\times$ height). The similar material simulation test should meet the requirements that the model is similar to the movement of all corresponding points in the entity; that is, the velocity, acceleration, and movement time of each corresponding point should be proportional. The determined similar constants of the model are listed in Table 1. In the simulation test, excavation was simulated along the strike direction of the working face, to simulate mining height and length of $4.4 \mathrm{~m}$ and $180 \mathrm{~m}$ and the height of overlying strata of $100 \mathrm{~m}$. The method of applying an external force to compensate for the load was adopted to realize uniform loading of the unstimulated rock strata. The boundary coal pillars with a width of $60 \mathrm{~cm}$ were set on both sides of the model to eliminate the influences of boundary effects. In the similar materials, fine sand was used as aggregates and lime and gypsum were used as binding materials. Mica powder was utilized to simulate weak planes, such as beddings and joint fractures in strata, and rock layers with different lithology were simulated by changing the proportions of aggregates and binding materials [26]. Six observation lines were set in the model, and 25 displacement observation points were set on each observation line, and Table 2 shows the location parameters of monitoring lines. In the test, an electronic theodolite was used to observe displacement and the fracture development in overlying strata was recorded by a highdefinition digital camera. Moreover, the development heights of the caving zone and the fracture zone were measured by a steel rule.

In accordance with the test, during the mining process of the working face, the roof fractures experience evolution from pressure relief, unstabilization, crack initiation, and intermittent vertical propagation of fractures from opening to shrinkage to closure under periodic roof weighting. Moreover, an obvious asymmetry is found in the evolution process. Such an evolution process has an important influence on CBM migration and enrichment in goaf, and caving patterns of roof during mining the working face are demonstrated in Figure 3.

As shown in the figure, migration characteristics of roof strata and evolution laws of fractures in overlying strata in the mining process of the working face are roughly divided into two stages: the first is the intermittent opening and closure of fractures in overlying strata. For example, when the coal seam is mined to $70-100 \mathrm{~m}$, the development height of fractures in overlying strata gradually rises in a large amplitude with mining of the coal seam. However, horizontally bed-separation fractures and longitudinally through-going fractures are mainly found in overlying strata and macroscopic bedseparation fractures are formed in a certain range of overlying strata in this stage (Figures 3(a) and 3(b)). The second is the stable development stage of fractures in overlying strata. For instance, when the coal seam is mined to $110-180 \mathrm{~m}$, the increased amplitude of development height of fractures in overlying strata reduces. The development height of fractures in overlying strata tends to be stable when mining to $180 \mathrm{~m}$ and basically reaches the upper boundary of the model. Fractures in overlying strata in the middle part of goaf are gradually compacted and fractures in overlying strata close to the sides of the open-off cut and the head of working faces are developed. A lot of horizontally bed-separation fractures and longitudinally through-going fractures are formed, which provide a place for CBM enrichment in goaf. In the meanwhile, they offer advantageous channels for cross-layer flow of CBM in goaf. This area can be used as a key area for CBM drainage (Figures 3(c) and 3(d)).

Based on the above analysis, as the working face is mined, fractures in overlying strata are mainly distributed on both sides of the working face, while fractures developed in the middle part are compacted due to extrusion of overlying strata. Therefore, the evolution laws of migration of roof strata and fracture development in the mining of the working face are shown as follows: because the influence range of mining-induced failure is gradually reduced with a mining activity point as the center, the failure range of roof strata on both sides of the working face will be damaged at a certain angle with the strike direction of the coal seam and the damaged strata rotate and sink under the action of hinge force with the undamaged ones. In addition, because of different deflections, fractures develop between upper and lower strata, and the fractures in strata in the middle part of the working face are gradually compacted because the hinge force between the adjacent strata is smaller than 


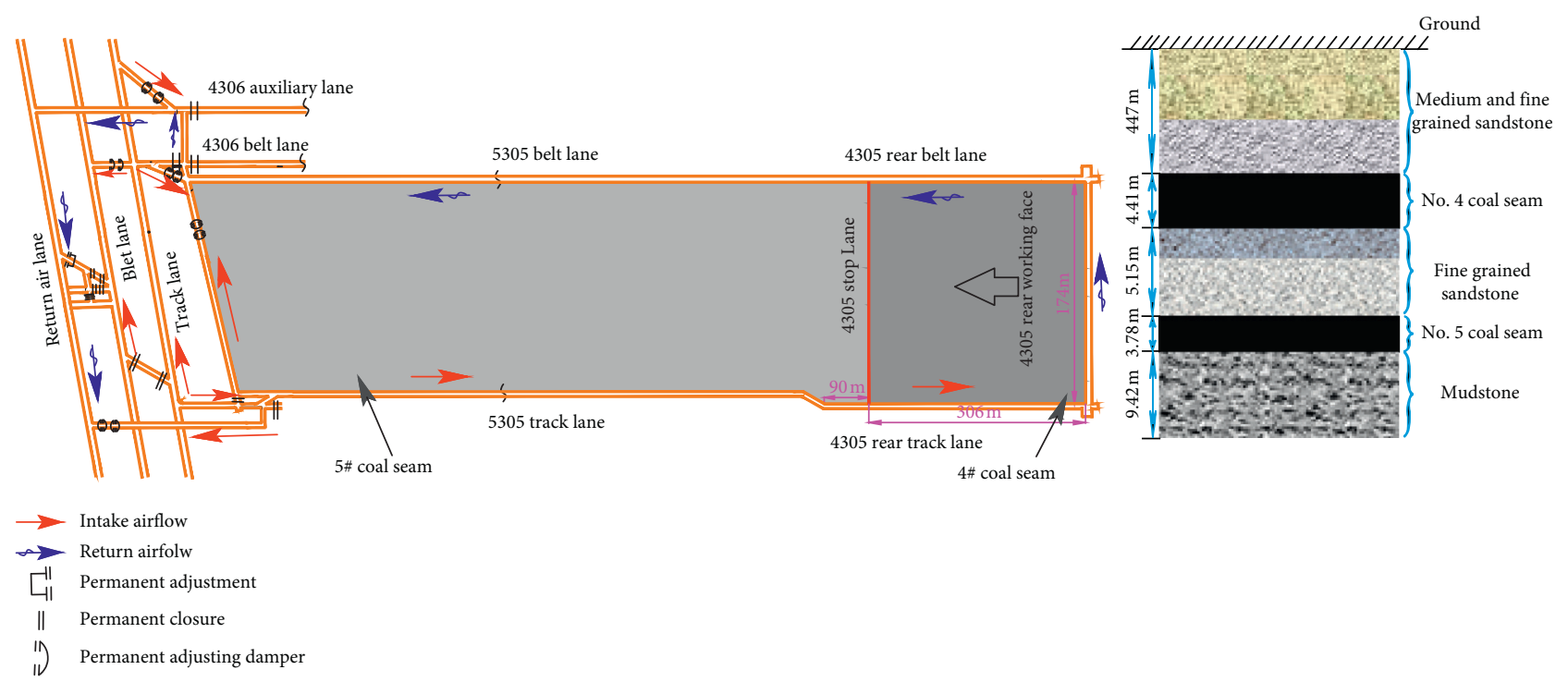

FIgURE 1: Layout of the working face and lithologic characteristics of overlying strata.

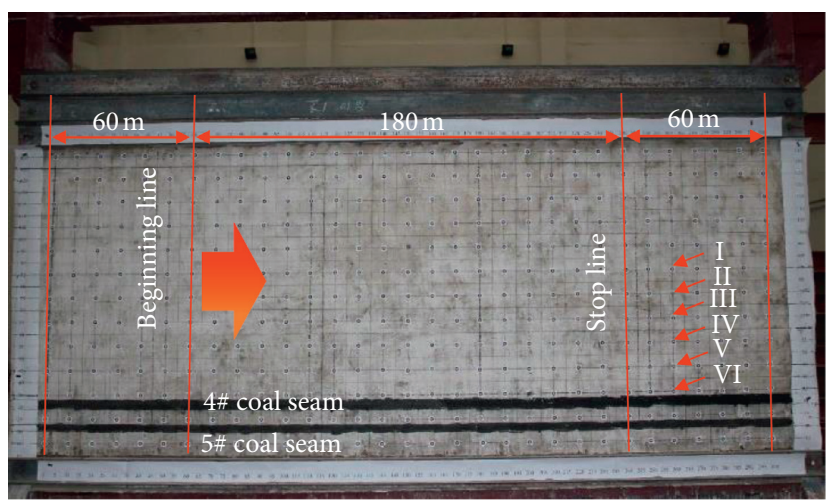

Figure 2: Model for similar simulation test.

TABLE 1: Main similar constants of the simulation test.

\begin{tabular}{lcccccc}
\hline $\begin{array}{l}\text { Model dimensions/ } \\
(\mathrm{mm} \times \mathrm{mm} \times \mathrm{mm})\end{array}$ & $\begin{array}{c}\text { Geometric } \\
\text { similarity }\end{array}$ & $\begin{array}{c}\text { Similar bulk } \\
\text { density }\end{array}$ & $\begin{array}{c}\text { Similar constant } \\
\text { time }\end{array}$ & $\begin{array}{c}\text { Poisson's } \\
\text { ratio }\end{array}$ & $\begin{array}{c}\text { Stress } \\
(\mathrm{MPa})\end{array}$ & $\begin{array}{c}\text { Intensity } \\
(\mathrm{MPa})\end{array}$ \\
\hline $1,800 \mathrm{~mm} \times 160 \mathrm{~mm} \times 1,500 \mathrm{~mm}$ & 100 & 1.625 & 10 & 1 & 7.9 & 16 \\
\hline
\end{tabular}

TABle 2: Parameters of model monitoring lines.

\begin{tabular}{lccc}
\hline Survey line & Line position & Number & Point interval $(\mathrm{cm})$ \\
\hline I & $52 \mathrm{~m}$ above the roof of $4 \#$ coal seam & 25 & 10 \\
II & $42 \mathrm{~m}$ above the roof of $4 \#$ coal seam & 25 & 25 \\
III & $32 \mathrm{~m}$ above the roof of $4 \#$ coal seam & 25 & 10 \\
IV & $22 \mathrm{~m}$ above the roof of 4\# coal seam & 25 & 10 \\
V & $12 \mathrm{~m}$ above the roof of 4\# coal seam & 25 & 10 \\
VI & $2 \mathrm{~m}$ above the roof of 4\# coal seam & 10 \\
\hline
\end{tabular}

the gravity of overlying strata. The fracture development zones on both sides of the working face are distributed in different spatial patterns due to different failure angles of strata on both sides of the working face; that is, asymmetric-oblique-quadrilateral development bodies are formed. 


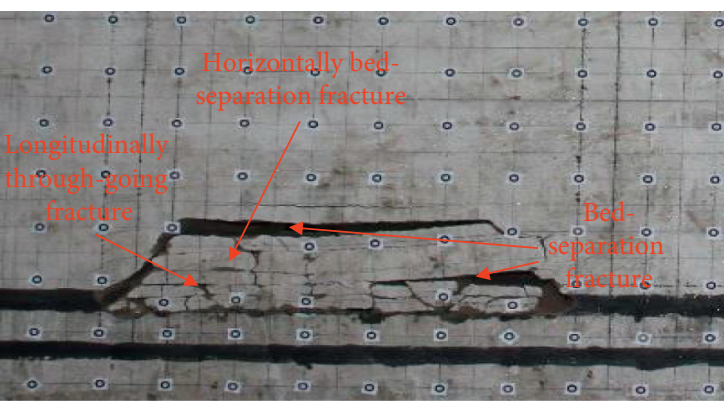

(a)

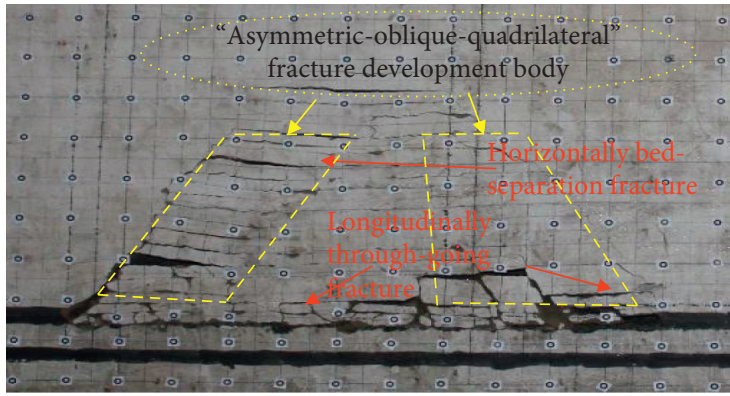

(c)

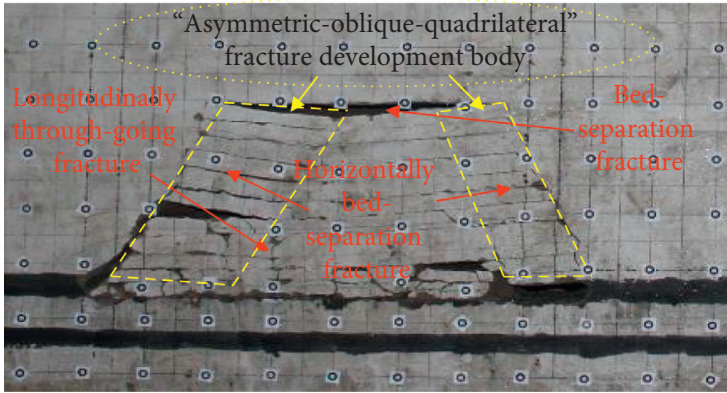

(b)

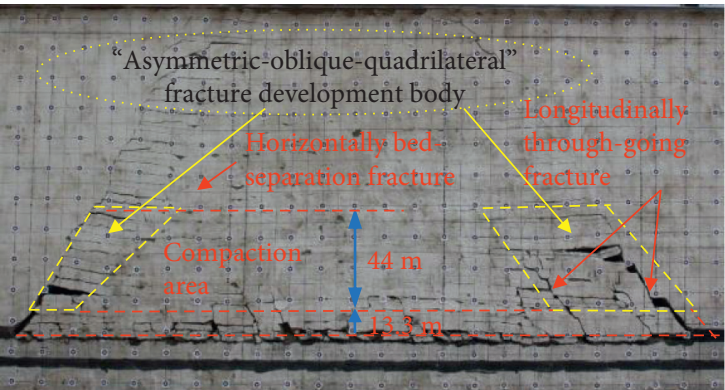

(d)

Figure 3: Fracture fields in overlying strata under different mining distances. (a) $70 \mathrm{~m}$, (b) $100 \mathrm{~m}$, (c) $110 \mathrm{~m}$, and (d) $180 \mathrm{~m}$.

3.2. Quantitative Analysis on Spatial Distribution Patterns of Mining-Induced Fractures. When the working face advances to the stop line $(180 \mathrm{~m})$, fracture development in overlying strata is stable (Figure 4) and is analyzed by grey processing method in this case. Owing to fracture frequency in overlying strata which can reflect distribution characteristics of fracture density, the fracture frequency can characterize the number of channels for CBM flow in fractures. Affected by the compaction in the middle part of the mining-induced fracture fields, the opened fractures may be closed, which is not conducive to CBM flow. However, the distribution of fracture density in overlying strata provides an opportunity for CBM flow. Therefore, the distribution of fracture frequency of overlying strata under stable fracture development is illustrated in Figure 5.

As shown in Figure 4, fractures in overlying strata are mainly distributed in oblique-quadrilateral fracture development zones above the open-off cut and the head of the working face. However, strata in the middle part of goaf are compacted due to the caving of overlying strata so that the fractures developed previously therein are closed under extrusion of caving strata. Based on the distribution of fracture frequency of overlying strata under stable fracture development, it is obtained that, in the oblique-quadrilateral fracture development zone above the open-off cut, strata with a normal distance of 20-40 m from the open-off cut along tendency direction of the coal seam are in the concentrated development zone of fractures, of which the fracture frequency is high and the fractures develop up to an elevation of $40 \mathrm{~m}$ in the vertical direction of the coal seam. In the oblique-quadrilateral fracture development zone above the head of the working face, fractures are developed in strata about $40 \mathrm{~m}$ from the working face along the tendency

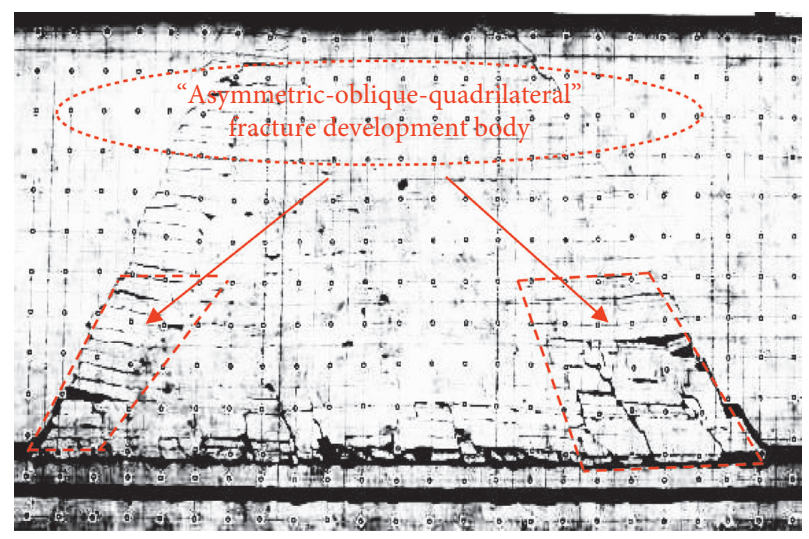

FIGURE 4: Grey processing analysis on distribution of fracture development in overlying strata.

direction of the coal seam where the fracture frequency is high. The highest level of fracture development along the vertical direction of the coal seam is found at $40 \mathrm{~m}$. In the areas extending from the middle part of the goaf, frequency shows a downward trend; that is, the strata in the middle part of the goaf are completely compacted by overlying strata, which leads to a low degree of fracture development and extrusion and closure of the developed fractures. At the same level, the number of through-going fractures in the obliquequadrilateral fracture development zone on the side of the head of the working face is usually larger than that on the side of the open-off cut. However, the development height of bed-separation fractures in the oblique-quadrilateral fracture development zone on the side of the open-off cut is larger than that on the coal wall side of the working face. 


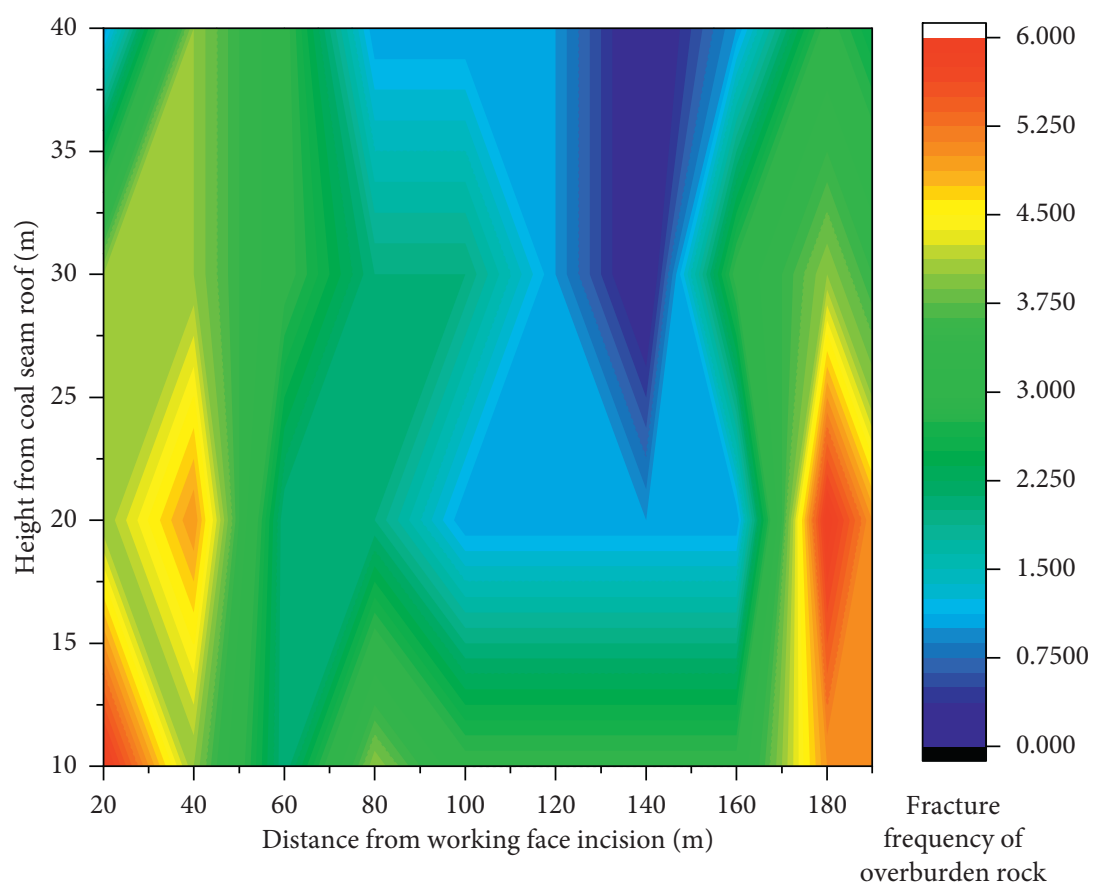

FIgURE 5: Distribution of fracture frequency.

3.3. Evolution Characteristics of the Asymmetric-ObliqueQuadrilateral Fracture Development Zone in Overlying Strata. Based on the above similar material simulation results, it is found that the fractures (bed-separation fractures and through-going fractures) in overlying strata are mainly distributed on both sides of the working face (the open-off cut and the head of the working face) during the mining process; the fractures are found to be distributed in a pattern forming the asymmetric-oblique-quadrilateral fracture development zone (Figure 6). However, distribution patterns of fractures in overlying strata in fracture development zones on both sides of the working face are subjected to different degrees of influences of mining-induced failure and extrusion of overlying strata, so the types of fracture development and interconnections are distinct. Therefore, to quantitatively characterize distribution patterns of bedseparation and through-going fractures in oblique-quadrilateral fracture development zones above the open-off cut and head of the working face, the following assumptions are made on the caving process of strata [27].

(1) The overlying strata under critical mining are taken as a research object

(2) The research object is nearly horizontal and isotropic in the same layer

(3) The ruptured structure of the research object conforms to a model of voussoir beam structure and the ruptured rock blocks are cuboid

Because entity coal on sides of the open-off cut and head of working face is not affected by mining, strata above them are not ruptured and collapse. For strata influenced by mining, the upper and lower strata are separated due to different deflections and the hinged interaction between ruptured rock blocks leads to different separation patterns in each layer. Therefore, slant rupture lines are formed along the side of the open-off cut and the side of the head of the working face to the overlying strata above, that is, rupture lines on both sides of the open-off cut and head of working face (Figure 7). The angles of the rupture lines on the sides of the open-off cut and head of the working face with the roof of the coal seam are defined as rupture angles $\alpha$ and $\beta$, respectively. Each layer of strata will form a voussoir beam structure taking the rupture lines on both sides of overlying strata as rupture points. Based on the above analysis, the oblique-quadrilateral fracture development zones on sides of the open-off cut and head of the working face are formed in overlying strata above the working face by taking rupture lines on both sides as baselines.

Therefore, the caving patterns of overlying strata along rupture lines on both sides are characterized as a simplified model in Figure 7. It can be seen from the figure that rupture angles $\alpha$ and $\beta$ on both sides of the working face with overlying strata are different due to different structures of overlying strata and caving modes. Therefore, mining-induced fractures in overlying strata on both sides of the working face present an asymmetric-oblique-quadrilateral fracture development zone in terms of the longitudinal direction and have an asymmetricoblique-quadrilateral fracture development body in terms of the spatial distribution pattern. The rupture angles $\alpha$ and $\beta$ on both sides of rupture lines in overlying strata are key rupture angles in this asymmetric-oblique-quadrilateral fracture development zone.

In order to facilitate analysis of the development width of the asymmetric-oblique-quadrilateral fracture development zone along the strike direction of the coal seam in the overlying strata, the first layer of strata on the side of the head of the working face was taken as a research object. As it 


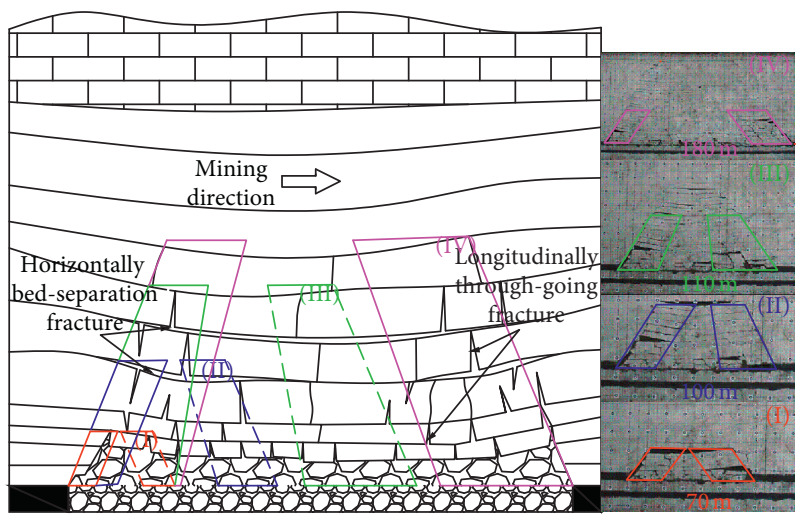

(a)

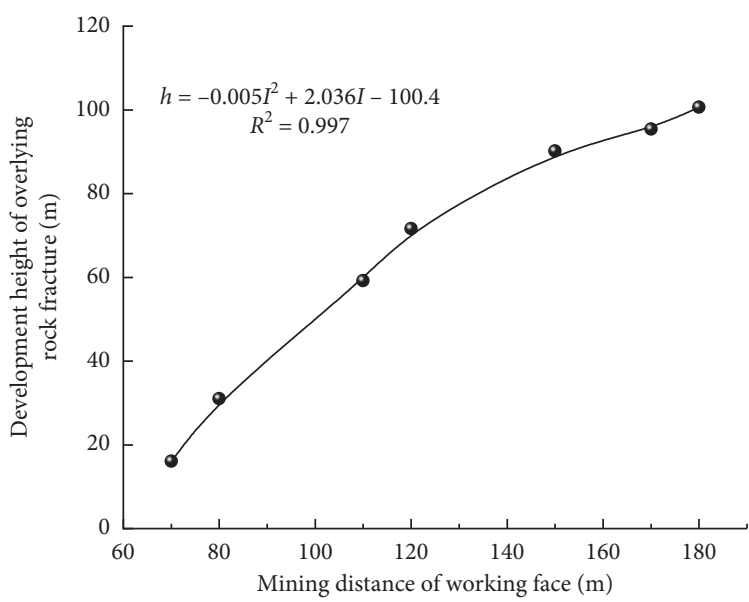

(b)

FIGURE 6: The relationship between mining distance of the working face and caving height of caving zone.

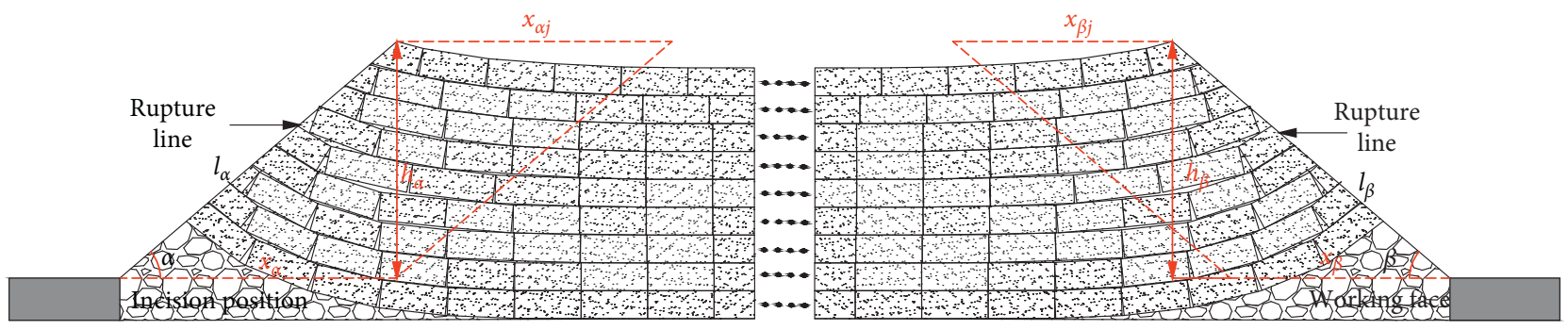

FIGURE 7: Simplified model of the asymmetric-oblique-quadrilateral fracture development zone in overlying strata.

is previously assumed that the ruptured rock blocks in the model are cuboid, the distribution of rock blocks in the first layer on the side of the head of the working face is demonstrated in Figure 8.

Assuming that the length and width of rectangular rock blocks are $a$ and $b$ and the angles between rock blocks $1,2,3$, $\ldots, m \ldots n$ and the strike direction of the coal seam are $\varphi_{1}, \varphi_{2}$, $\varphi_{3}, \ldots, \varphi_{m} \ldots \varphi_{n}$, under the influence of mining, strata will cave and rupture at the point of overlapping fracture lines, that is, the rupture point. The fractured rock blocks in strata rotate under hinged interaction and fractures appear between rock blocks. As this continues, the fracture development zone is formed by the ruptured strata. When $n$ rock blocks overlap on the rupture line, it is the boundary for the development of the fracture zone. While the $m_{\mathrm{th}}$ rock block is nearly horizontal, namely, $\varphi_{m}=0$, bed-separation fractures will stop developing. Therefore, the length of a bending section in the voussoir beam structure is approximately equal to the width of the fracture development zone. As a result, the development width $x_{\beta 1}$ in the first layer in the oblique-quadrilateral fracture development zone can be characterized as follows:

$$
x_{\beta 1}=a \cos \varphi_{11}+a \cos \varphi_{21}+a \cos \varphi_{31}+\cdots+a \cos \varphi_{n 1}=\sum_{0}^{n} a \cos \varphi_{i 1} .
$$

The development width $x_{\beta j}$ of the jth layer in the fracture development zone is expressed as $x_{\beta j}=\sum_{0}^{n} a \cos \varphi_{i j}$. Herein, $\varphi_{i j}$ represents the angle between the $i$ th rock block in the $j$ th layer and the strike direction of the coal seam and the jth layer is the highest development level of the asymmetric fracture development zone.

According to the displacement laws obtained through geometric approximation and full structure calculation, the following formula is obtained:

$$
\cos \varphi_{i j} \approx \varphi_{i j}
$$

The development width of the $j^{\text {th }}$ layer in the obliquequadrilateral fracture development zone can be expressed as follows:

$$
x_{\beta j}=\sum_{0}^{n} a \cdot \varphi_{i j} .
$$

According to attenuation laws of the bulking factor in the fracture zone of overlying strata in the previous research [28], the following formula is obtained:

$$
C_{Z}=C^{\prime}-\eta \ln z
$$

where $C^{\prime}, z$, and $\eta$ indicate the bulking factor of the lower boundary of the fracture zone, distance from the coal seam, and attenuation coefficient, respectively. 


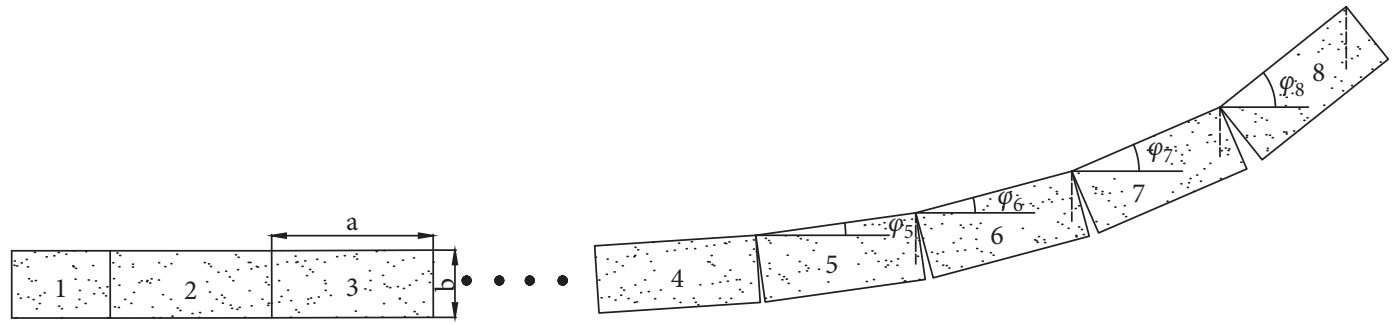

FIGURE 8: Distribution of rock blocks in the first layer on the side of the head of the working face.

By combining the characteristics of existing surface subsidence lines (the curve is convex on the side of the coal wall and concave near the goaf) and the mechanical model of voussoir beams, the displacement function of voussoir beams is shown as follows:

$$
W_{x}=W_{0}\left[1-\frac{1}{1+e^{(x-0.5 l) / a}}\right]
$$

where $x$ represents the distance $(m)$ from the mining boundary and the value of $a$ is $0.25 l$.

$$
\begin{gathered}
W_{0}=M-\sum h^{\prime}\left(C_{p}^{\prime}-1\right), \\
l=h \sqrt{\frac{\sigma_{t}}{3 q}},
\end{gathered}
$$

where $W_{x}, \sum h^{\prime}$, and $l_{i}$ indicate the displacement curve $(m)$ of voussoir beams, the distance $(m)$ from the voussoir beam structure to the roof of the coal seam, and the length $(m)$ of ruptured rock in the $i$ th key stratum, respectively; $W_{0}, \sigma_{t}$, and $q$ denote the final settlement $(\mathrm{m})$, tensile strength $(\mathrm{MPa})$ of rock blocks, and load ( $\mathrm{MPa})$ borne by rock blocks, respectively.

By combining formulas (2), (7), (8), and (9), the following formula is obtained:

$$
\varphi_{i j}=\frac{\left[M-\sum h^{\prime}\left(C_{p}^{\prime}-1\right)\right]\left[1-\left(1 / 1+e^{2}\right)\right]}{h \sqrt{\left(\sigma_{t} / 3 q\right)}} .
$$

In the oblique-quadrilateral fracture development zones on both sides above the working face, rupture lines $l_{a}$ and $l_{\beta}$ on both sides are taken as baselines to form the asymmetricoblique-quadrilateral fracture development zones in overlying strata. $h_{a}$ and $h_{\beta}$ represent the maximum development heights of the fracture development zones. Based on Regulations for Setting Coal Pillar and Mining under Buildings, Water Bodies, Railways and Main Roadways (2017), the theoretical calculation formula for the height of the fracture zone in medium and hard strata is shown as follows:

$$
h=\frac{100 \sum M}{1.6 \sum M+3.6} \pm 5.6 \text {. }
$$

Based on formulas (1), (3), and (9), the distribution area $S_{\beta}$ of the oblique-quadrilateral fracture development zone in overlying strata on the side of the head of the working face can be obtained.

$$
s_{\beta}=\frac{\left(x_{\beta 1}+x_{\beta j}\right) h_{\beta}}{2}=\frac{a\left(\sum_{0}^{n} \varphi_{i 1}+\sum_{0}^{n j} \varphi_{i 1}\right) h}{2} .
$$

Therefore, the distribution area $S_{\alpha}$ of the obliquequadrilateral fracture development zone in overlying strata on the side of the open-off cut is expressed as follows:

$$
s_{\alpha}=\frac{\left(x_{\alpha 1}+x_{\alpha j}\right) h_{\alpha}}{2}=\frac{a\left(\sum_{0}^{n} \varphi_{i 1}+\sum_{0}^{n j} \varphi_{i j}\right) h}{2} .
$$

Therefore, based on formulas (3), (10), and (11), the distribution parameters of fractures in the asymmetricoblique-quadrilateral fracture development zones in overlying strata of the 4305 rear working face in Shaqu No. 1 Coal Mine can be obtained.

For the fracture development zone on the side of the open-off cut, $x_{\alpha 1}=18.9 \mathrm{ml}, \quad x_{\alpha j}=22.68 \mathrm{~m}, \quad$ and $S_{\alpha}=943.0344 \mathrm{~m}^{2}$.

For the fracture development zone on the side of the head of the working face, $x_{\beta 1}=45.36 \mathrm{~m}, x_{\beta j}=37.8 \mathrm{~m}$, and $S_{\beta}=1886.0688 \mathrm{~m}^{2}$.

\subsection{Numerical Simulation Analysis on Caving Characteristics} of Surrounding Rock. As the working face advances, roof rock mass in goaf is strongly discontinuous in terms of pattern and structure and the movement and failure of surrounding rock under the influence of mining are simulated with a three-dimensional discrete element code (3DEC) method to reveal distribution laws of fractures. Based on the basic conditions of roof and floor of the 4305 rear working face in Shaqu Coal Mine, a 3DEC numerical model containing coal pillars was built, with the length, width, and height of $280 \mathrm{~m}, 2 \mathrm{~m}$, and $114.07 \mathrm{~m}$, as shown in Figure 9. The numerical model was simplified into 27 different strata and the equivalent load was applied on the top boundary of the model. The equivalent load was calculated by the following formula: by substituting the distance of $390.49 \mathrm{~m}$ from the surface into the following formula, it is calculated that $9.70 \mathrm{MPa}$ of force should be applied. The equivalent load is expressed as follows:

$$
q=\rho g \sum h
$$

where $q$ and $h$ indicate the equivalent load $\left(\mathrm{N} / \mathrm{m}^{2}\right)$ and distance $(m)$ from the top of the model to the ground surface, respectively; $g$ represents the gravitational acceleration and values $9.8 \mathrm{~m} / \mathrm{s}^{2}$. 


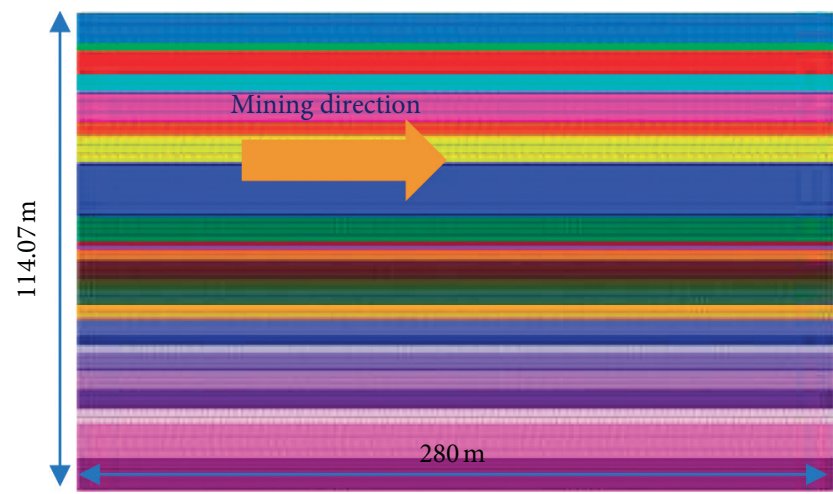

(a)

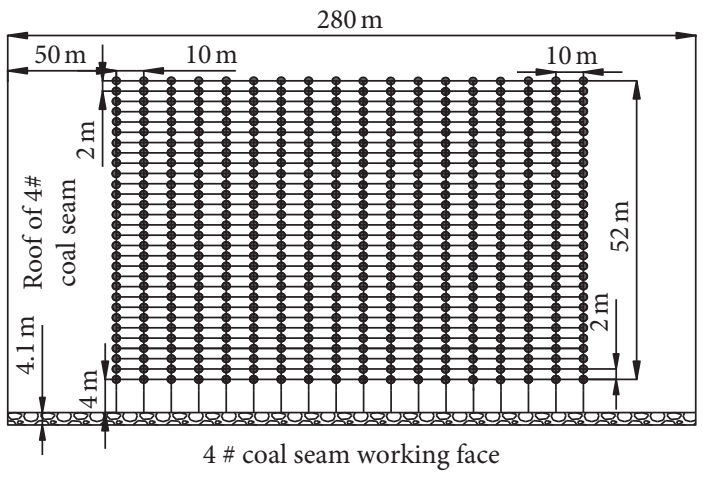

(b)

FIgURE 9: 3DEC numerical simulation. (a) 3DEC numerical model. (b) Layout of measuring points in the model.

There are six free surfaces in the model. Except that the horizontal displacement is fixed on the top boundary, horizontal and vertical displacements are fixed on the other five boundaries. The Mohr-Coulomb criterion was adopted as the constitutive relationship of the rock mass. The physical and mechanical parameters of coal and rock in the numerical simulation were data collected in the field and laboratory tests.

As the working face advances, the following phenomena successively occur in overlying strata on the working face. These phenomena include gradual development of fractures in immediate roof, large-area caving of immediate roof, first weighting of immediate roof and rupture of key strata, development of lots of fractures, stepped subsidence and cutting of roof along coal wall, and final formation of obvious bending and subsidence zone in the fracture zone. When the working face is advanced to $180 \mathrm{~m}$, the fractures in the roof further develop and the height of the fracture zone further increases. Moreover, the strata in the rear have been recompacted and the caving characteristics of overlying strata are basically stabilized (Figures 10-13).

It can be seen from the overall distribution area of the fracture zone that fractures in overlying strata are mainly concentrated right above the open-off cut and head of the working face and in the area about $40-45 \mathrm{~m}$ away from the roof of the working face. Moreover, a spatial distribution pattern of the fracture development zone similar to that in the previous section is formed; that is, fractures in overlying strata on sides of the open-off cut and head of working face are asymmetric-oblique-quadrilateral. However, due to the extrusion of large-area caved strata right above the goaf, internal fractures are gradually compacted and some fractures are closed. In the mining process, caving and migration of overlying strata of roof and change characteristics of stress are shown in the following figures.

As shown in Figure 14, when the working face of 4 \# coal seam advances to $180 \mathrm{~m}$ (finishing tunneling in the strike direction), vertical displacement of each basic point at different heights of the roof decreases to different degrees. Furthermore, as the distance from the open-off cut is getting farther, the vertical displacement of the basic points at different heights of the roof first increases and then

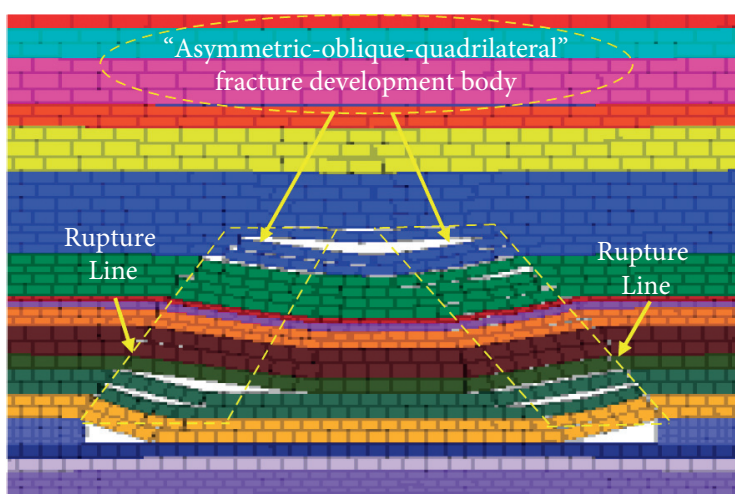

Figure 10: Mining to $70 \mathrm{~m}$.

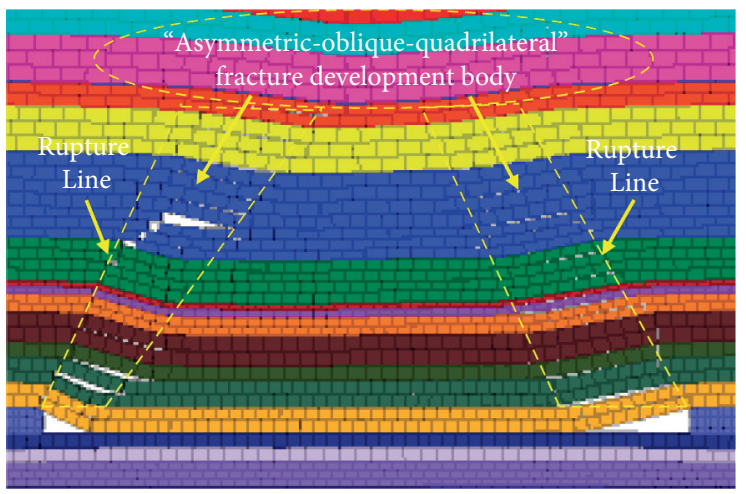

FIgURE 11: Mining to $100 \mathrm{~m}$.

decreases. At position $4 \mathrm{~m}$ away from the roof of the coal seam, vertical displacement of strata changes largely and the maximum displacement is $3.5 \mathrm{~m}$. Within the range $14-24 \mathrm{~m}$ away from the roof, vertical displacement of strata shows a basically consistent change trend, indicating that strata there have the same caving characteristics under mining influence. At position $30 \mathrm{~m}$ away from the roof, the vertical displacement jumps from that at location $44 \mathrm{~m}$ away from the roof, which results in a large difference, indicating that there is a certain separation layer. As the working face advances $0-40 \mathrm{~m}$ and $140-180 \mathrm{~m}$, vertical displacement at measuring 


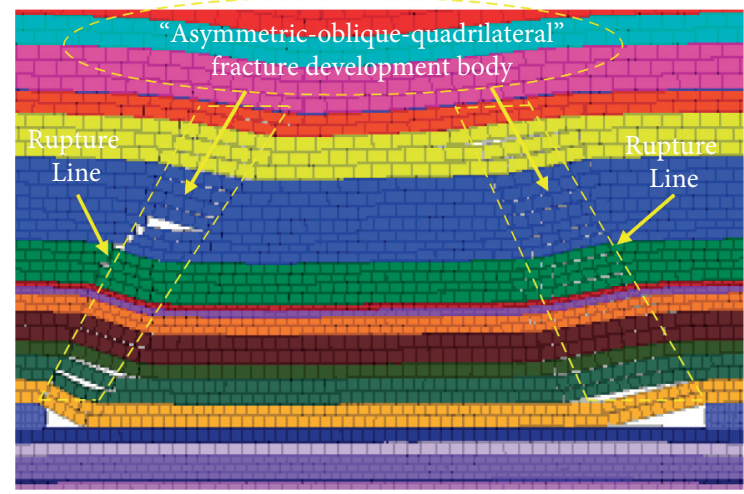

Figure 12: Mining to $110 \mathrm{~m}$.

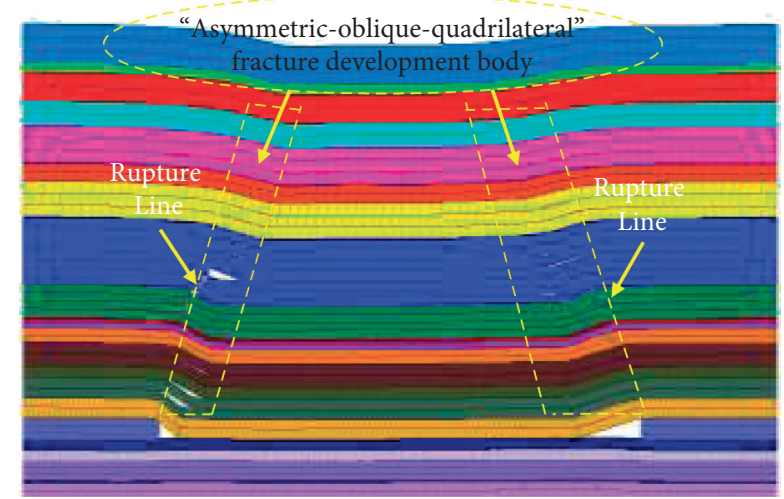

Figure 13: Mining to $180 \mathrm{~m}$.

points in each layer changes suddenly. This implies that a lot of fractures are generated and developed in overlying strata within a range of $40 \mathrm{~m}$ from both the open-off cut and the head of the working face (fractures will open or close or coalesce with each other).

Monitoring results of changes of vertical stress in the roof of the working face (Figure 15) demonstrate that, with the continuous advance of the working face, vertical stress in each layer varies to different degrees. This suggests that a lot of open or closed fractures are generated in overlying strata in the vertical range of 4-44 $\mathrm{m}$ away from the roof of the working face. Vertical stress at position $30 \mathrm{~m}$ above the roof has a largely different change rate from that at $44 \mathrm{~m}$. In addition, during the later stage of mining the working face, the changes of vertical stress in strata $42 \mathrm{~m}$ away from the roof present an obvious phenomenon surpassing others; that is, the change rate of vertical stress in strata in this layer is higher than that in other layers. Therefore, this indicates that layer separation appears within a vertical range of 30-44 m away from the roof of the coal seam.

Based on changes of vertical displacement and stress of overlying strata, the optimal development height of the asymmetric-oblique-quadrilateral fracture development zone in overlying strata along the vertical direction of the roof is $30-44 \mathrm{~m}$ away from the roof. The optimal development width of the fracture development zone along the

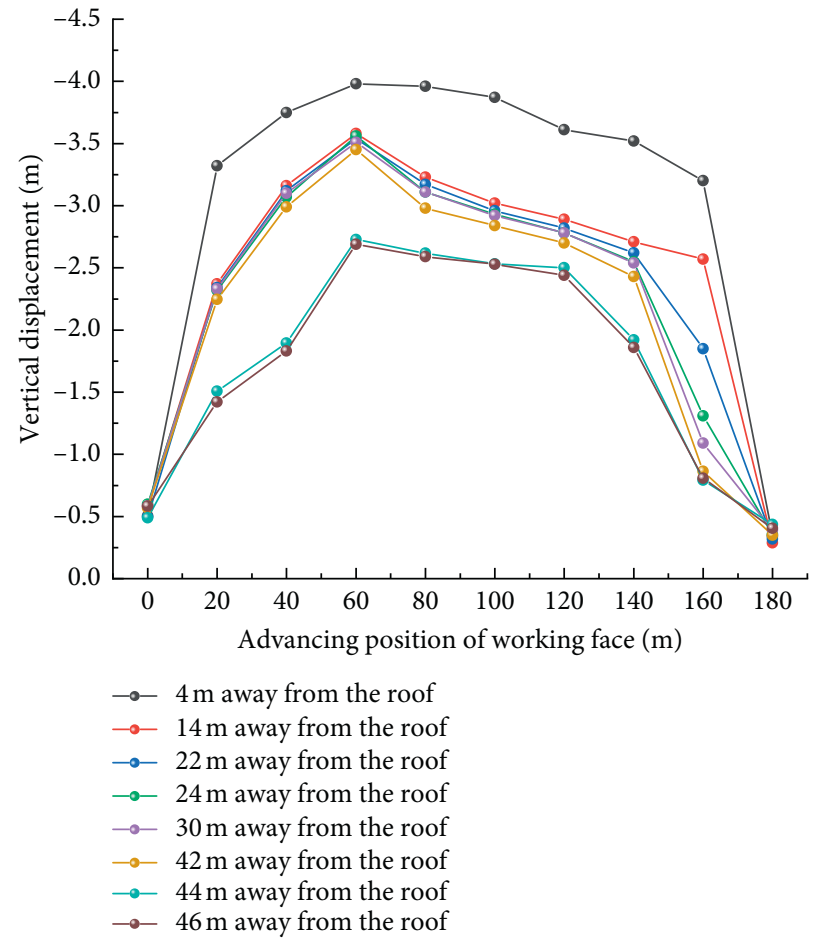

FIgURE 14: Monitoring results of changes of vertical displacement of the roof of the working face.

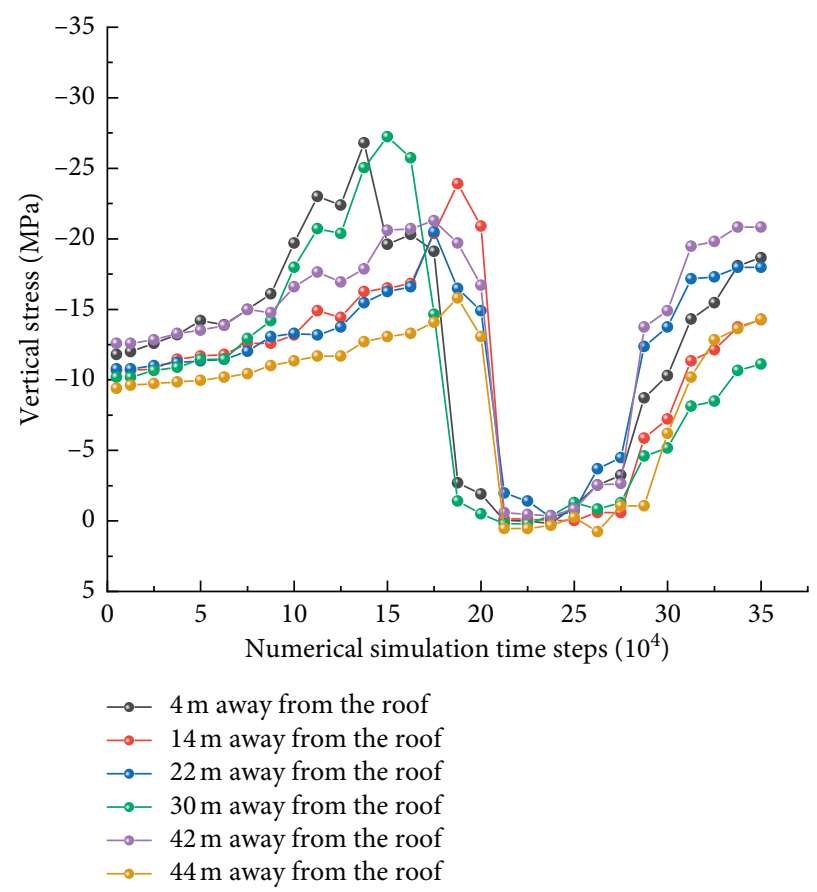

FIgURE 15: Monitoring results of changes of vertical stress in the roof of the working face.

strike direction of the coal seam is within $40 \mathrm{~m}$ from the sides of the open-off cut and the head of the working face. 


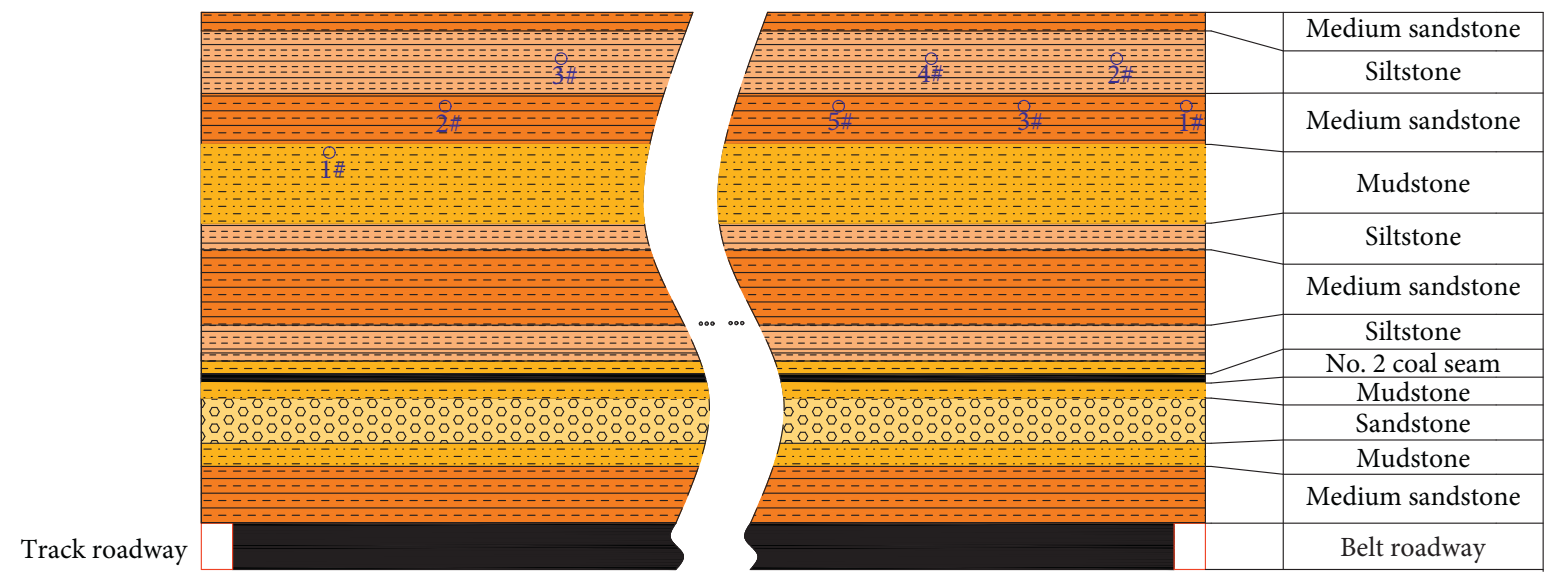

FIgURE 16: Schematic diagram of long-hole directional drilling in the fracture zone in overlying strata of the 4305 rear working face.

\section{Field Measurement of Areas Favorable for Mining-Induced Pressure-Relief CBM Drainage}

4.1. Determination of Areas Favorable for CBM Drainage in the Fracture Development Body. Based on the above research, it is found that there are asymmetric-obliquequadrilateral fracture development zones above the open-off cut and head of the working face. Moreover, fracture development degree and pressure-relief degree in the fracture development zones are higher than those in other areas in overlying strata under the same mining intensity. Therefore, bed-separation fractures and through-going fractures in the fracture development zone provide advantageous channels for pressure-relief CBM migration in the coal seam. In this case, if the drainage is conducted in this fracture body, CBM concentration in the upper corner of the working face and return airway can be greatly reduced. Therefore, the development degree of the asymmetric-oblique-quadrilateral fracture development zone is directly correlated with the efficiency of mining-induced pressure-relief CBM drainage.

Therefore, by taking the 4305 rear working face in Shaqu No. 1 Coal Mine as the engineering background, the theoretical distribution height $h$ of the fracture zone in overlying strata can be calculated as $35.78-44.78 \mathrm{~m}$ according to formula (9). By combining with similar material simulation results of the 4305 rear working face in the mine and 3DEC numerical simulation results, the optimal development height $h$ of the asymmetric-oblique-quadrilateral fracture development zone in overlying strata of the working face is comprehensively determined as $32-44.78 \mathrm{~m}$.

It is difficult and dangerous to measure rupture angles on both sides of the fracture development body in the overlying strata of the 4305 rear working face in the field. Considering this, the similar simulation and numerical simulation results after stabilizing mining of the working face are used. Based on the result, the optimal development width $x_{\alpha 1}$ of the oblique-quadrilateral fracture development zone on the side of the open-off cut is 18.9-40 $\mathrm{m}$ and the optimal development width $x_{\alpha j}$ at the highest development layer is $22.68 \mathrm{~m}$. The oblique-quadrilateral fracture development zone on the side of the head of the working face has the optimal development width $x_{\beta 1}$ of $20-45.36 \mathrm{~m}$ and the optimal development width $x_{\beta j}$ at the highest development layer reaches $37.8 \mathrm{~m}$.

4.2. Parameter Design for Long Directional Boreholes in the Fracture Development Body. Based on the above analysis, by arranging long directional boreholes in the asymmetricoblique-quadrilateral fracture development zone in overlying strata of the 4305 rear working face, the precise pressure-relief CBM drainage in the fracture development body is realized. The development height $h$ of the fracture development zone ranges from $32 \mathrm{~m}$ to $44.78 \mathrm{~m}$ and the optimal development widths at the highest development layers of the fracture zone on the sides of the open-off cut and head of the working face are $22.68 \mathrm{~m}$ and $37.8 \mathrm{~m}$, respectively. Therefore, the design parameters for long directional boreholes are listed in Figures 16 and 17 and Table 3.

4.3. Result Analysis. As displayed in Figure 18, the amount of CBM drainage from $1 \#$ borehole on the side of the track roadway fluctuates frequently due to the influence of mining and it is about $0.6 \mathrm{~m}^{3} / \mathrm{min}$ on average. Although the amount of CBM drainage from $3 \#$ borehole also changes due to influences of mining, it only changes at a small amplitude and the average amount is about $0.3 \mathrm{~m}^{3} / \mathrm{min}$. This indicates that fracture development states in strata around $3 \#$ borehole are slightly affected by mining of the working face; that is, fractures are stably developed around the borehole. In this case, 3 \# borehole in overlying strata above the track roadway side should be located beyond the asymmetric-obliquequadrilateral fracture development zone in overlying strata of the 4305 rear working face. Therefore, for the fracture development zone on the side of the track roadway, $x_{a j} \leq 22.68 \mathrm{~m}$, and rupture line $l_{\alpha}$ of the fracture development zone should be out of the $1 \#$ borehole; namely, rupture angle $\alpha$ is $[74,90]$.

As displayed in Figure 19, the net amount of CBM drainage from $1 \#$ and $2 \#$ boreholes in the fracture zone on 

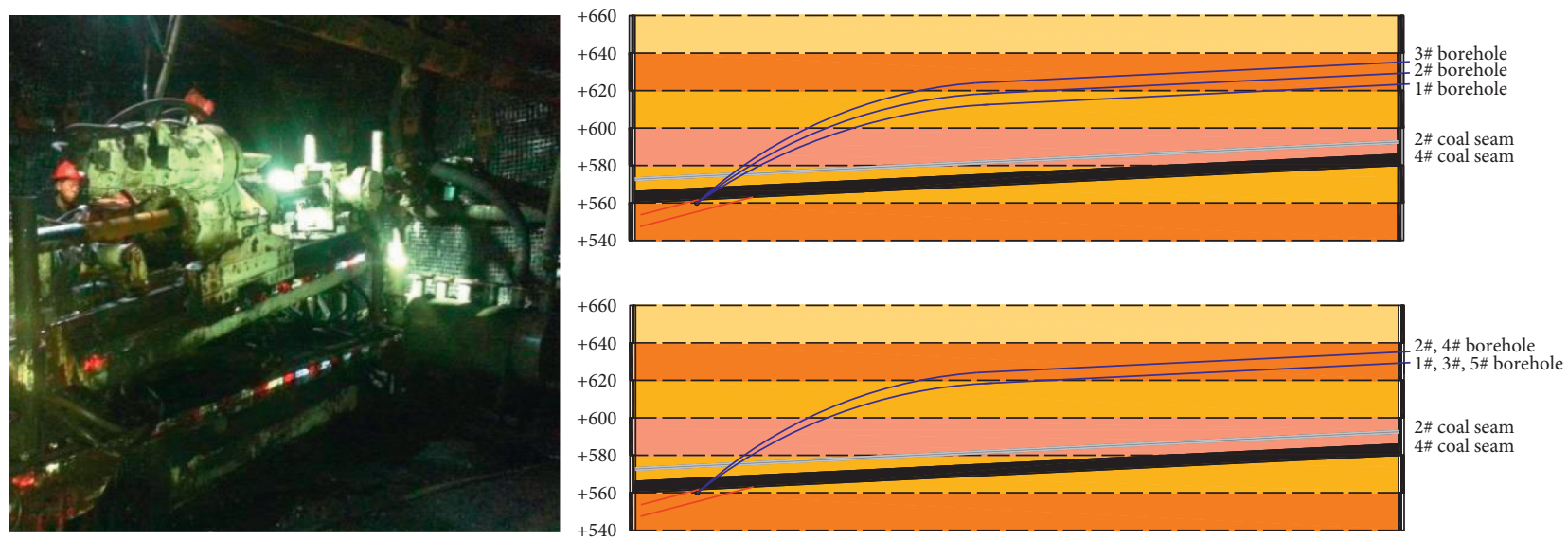

FIGURE 17: Site construction and trajectory of long-hole directional drilling in the fracture zone in overlying strata of the 4305 rear working face.

TABle 3: Parameters for borehole layout.

\begin{tabular}{|c|c|c|c|c|c|c|c|c|}
\hline \multirow{2}{*}{$\frac{\text { Borehole location }}{\text { Number of boreholes }}$} & \multicolumn{3}{|c|}{ Side of track roadway } & \multicolumn{5}{|c|}{ Side of belt roadway } \\
\hline & $1 \#$ & 2\# & 3\# & $1 \#$ & 2\# & 3\# & $4 \#$ & $5 \#$ \\
\hline Distance from roadway $(\mathrm{m})$ & 10 & 20 & 30 & 0 & 6 & 14 & 22 & 30 \\
\hline Layout layer height $(\mathrm{m})$ & 35.2 & 39.6 & 44 & 39.6 & 44 & 39.6 & 44 & 39.6 \\
\hline Borehole diameter $(\mathrm{mm})$ & 153 & 153 & 153 & 153 & 153 & 153 & 153 & 153 \\
\hline
\end{tabular}

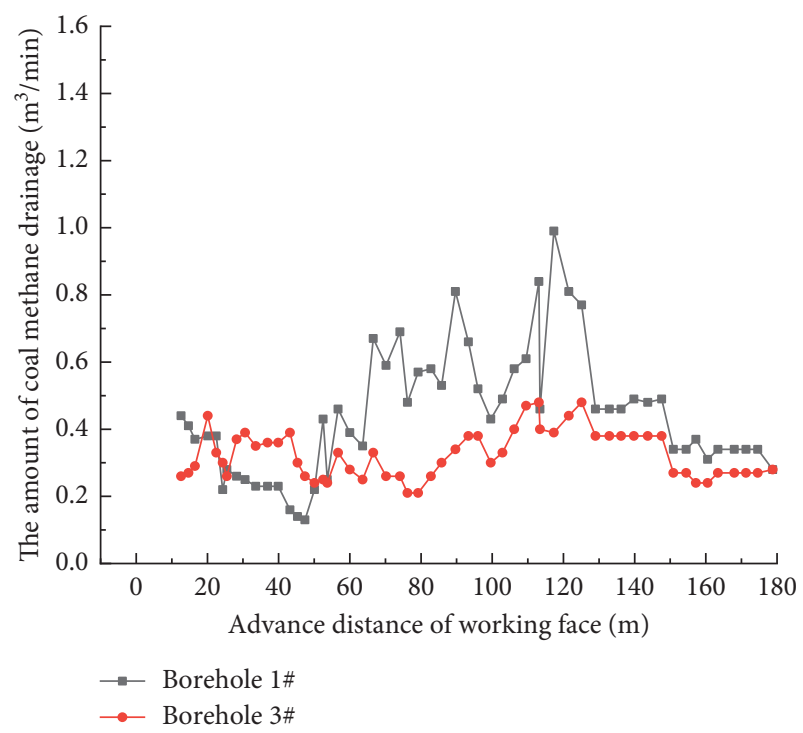

FIGURE 18: Data of CBM drainage from directional boreholes in the fracture zone on the side of the track roadway.

the side of the belt roadway is low and changes slightly during the advance of the working face and the average is about $0.05 \mathrm{~m}^{3} / \mathrm{min}$. This indicates that periodic caving of the roof of the 4305 rear working face has small influences on drainage effects of $1 \#$ and $2 \#$ boreholes and opening and coalescence of fractures in strata around the boreholes are not influenced by caving of the lower strata. Therefore, 1\# and $2 \#$ boreholes above the side of the belt roadway should

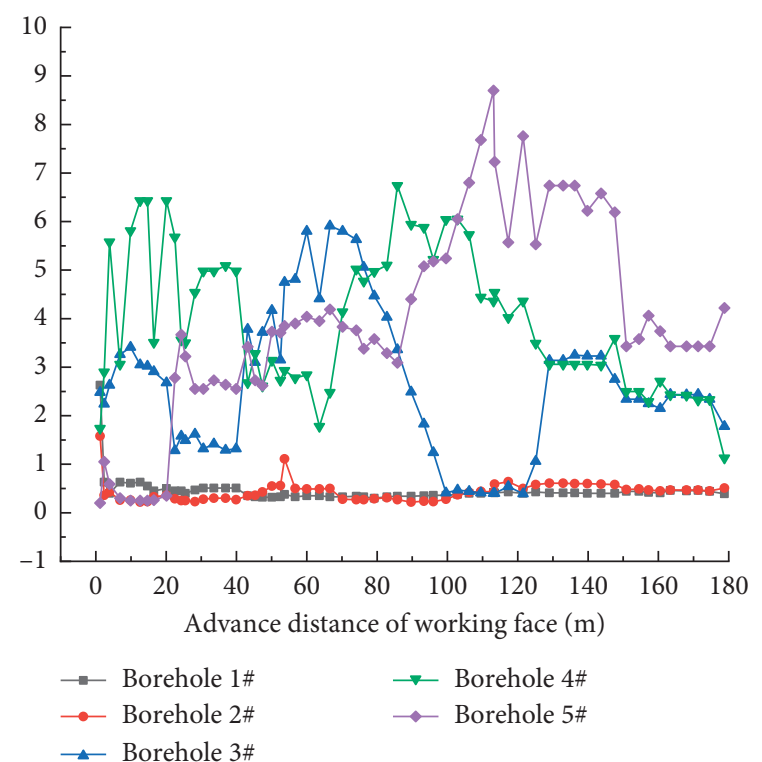

FIgURE 19: Data of CBM drainage from directional borehole in the fracture zone on the side of belt roadway.

be out of the rupture line in $l_{\beta}$ of the asymmetric-obliquequadrilateral fracture development zone in the overlying strata of the working face. However, as the working face advances, the amount of CBM drainage from 3\#, 4\#, and 5\# boreholes fluctuates frequently and it firstly rises and then reduces on the whole. This suggests that 3\#, 4\#, and 5\# boreholes are affected by period caving of roof and fractures 
in strata near these boreholes change in the following laws: development of primary fractures, initiation of lots of secondary fractures, coalescence of these fractures to form a channel for CBM flow, and then closure of some fractures due to mining. As a result, the amount of CBM drainage from boreholes decreases. Therefore, 3\#, 4\#, and 5\# boreholes should be located in the asymmetric-oblique-quadrilateral fracture development zone on the side of the belt roadway. In this case, the rupture line $l_{\beta}$ of the fracture development zone on the side of the belt roadway should be located between 2 \# borehole and 3 \# borehole, so the rupture angle $\beta$ should be $(70,82]$. In addition, with advance of the working face, the amount of CBM drainage from 5\# borehole is always larger than that from the other boreholes, indicating that strata around 5\# borehole are always in the fracture development zone, so $x_{\beta j} \geq 24 \mathrm{~m}$.

\section{Conclusions}

(1) Based on results of similar material simulation and numerical simulation, the intervals favorable for the development of mining-induced fractures in overlying strata of the 4305 rear working face in Shaqu No. 1 Coal Mine are shown as follows: the ranges $30-44 \mathrm{~m}$ from the roof of the coal seam in the vertical direction and within $40 \mathrm{~m}$ from the open-off cut of the working face or head of working face in the horizontal direction are areas where a lot of fractures are generated and developed.

(2) Affected by the mining of the working face, the inclined quadrilateral fracture development areas are formed in the overburden rock above the open-off cut and the head of the working face, respectively. Due to different rupture angles $\alpha$ and $\beta$ of the fracture development zones on both sides of overlying strata, mining-induced fractures in overlying strata along longitudinal direction are distributed in a pattern that forms the asymmetric, oblique, and quadrilateral fracture development zone. Furthermore, the asymmetric-oblique-quadrilateral fracture development body is formed in space, and the development widths of fracture development zones on both sides are $x_{\alpha 1}=18.9 \mathrm{~m}, x_{\alpha j}=22.68 \mathrm{~m}$, $x_{\beta 1}=45.36 \mathrm{~m}$, and $x_{\beta j}=37.8 \mathrm{~m}$, respectively. The distribution areas of the fracture development zones are $S_{\alpha}=943.0344 \mathrm{~m}^{2}$ and $S_{\beta}=1886.0688 \mathrm{~m}^{2}$, respectively.

(3) Fracture development state in the fracture development body in overlying strata is closely related to pressure-relief CBM seepage to form the asymmetric-oblique-quadrilateral fracture-seepage community in overlying strata. Finally, the rupture angles on both sides of the asymmetric-oblique-quadrilateral fracture development zones in overlying strata of the 4305 rear working face in Shaqu Coal Mine are determined to be $74^{\circ} \leq \alpha<90^{\circ}$ and $70^{\circ} \leq \beta \leq 82^{\circ}$. In addition, $x_{a j} \leq 22.68 \mathrm{~m}$ and $24 m \leq x_{\beta j} \leq 37.8 \mathrm{~m}$. If the drainage engineering is designed in this area, the efficiency of pressure-relief CBM drainage will be greatly improved and the safe production of mining space will be ensured [3, 22-28].

\section{Data Availability}

The data used to support the findings of this study are included within the article.

\section{Conflicts of Interest}

The authors declare that they have no conflicts of interest.

\section{References}

[1] A. T. Zhou, K. Wang, L. Li et al., "A roadway driving technique for preventing coal and gas outbursts in deep coal mines," Environmental Earth Sciences, vol. 76, no. 6, p. 236, 2017.

[2] X. Cheng, G. Zhao, Y. Li et al., "Evolution of overlying mining-induced fractured zone and pressure-relief methane drainage in soft rock protective seam," Journal of Mining \& Safety Engineering, vol. 37, no. 03, pp. 533-542, 2020.

[3] K. Wang and F. Du, "Coal-gas compound dynamic disasters in China: a review," Process Safety and Environmental Protection, vol. 133, pp. 1-17, 2020.

[4] L. Yuan, "Strategic thinking of simultaneous exploitation of coal and gas in deep mining," Journal of China Coal Society, vol. 41, no. 1, pp. 1-6, 2016.

[5] H. Wang, B. Tan, Z. Shao, Y. Guo, Z. Zhang, and C. Xu, "Influence of different content of $\mathrm{FeS} 2$ on spontaneous combustion characteristics of coal," Fuel, vol. 288, p. 119582, 2021.

[6] H. Wang, X. Fang, Y. Li, Z. Zheng, and J. Shen, "Research and application of the underground fire detection technology based on multi-dimensional data fusion," Tunnelling and Underground Space Technology, vol. 109, Article ID 103753, 2021.

[7] Z. Cheng, Y. Lu, S. Su et al., "Mechanism study on high efficiency gas drainage of high level strike long boreholes in gob roof," Coal Science and Technology, vol. 48, no. 02, pp. 136-142, 2020.

[8] M. Qian, J. Xu, and X. Miao, "Green technique in coal mining," Journal of China University of Mining\& Technology, vol. 32, no. 1, pp. 343-347, 2003.

[9] J. Xu and M. Qian, "Study and application of mining-induced fracture distribution in green mining," Journal of China University of Mininge Technology, vol. 33, no. 2, pp. 141-144, 2004.

[10] Y. Liu, Q. Zhang, J. Zhang et al., "Theoretical research on protective seam mining in full rock stratum and engineering application," Journal of Mining \& Safety Engineering, vol. 35, no. 1, pp. 146-154, 2018.

[11] F. Du, K. Wang, X. Zhang, C. Xin, L. Shu, and G. Wang, "Experimental study of coal-gas outburst: insights from coalrock structure, gas pressure and adsorptivity," Natural Resources Research, vol. 29, no. 4, pp. 2481-2493, 2020.

[12] F. Du and K. Wang, "Unstable failure of gas-bearing coal-rock combination bodies: insights from physical experiments and numerical simulations," Process Safety and Environmental Protection, vol. 129, pp. 264-279, 2019.

[13] M. Qian, "A study of the behavior of overlying strata in longwall mining and its application to strata control," in Proceedings of the Symposium on Strata Mechanics, pp. 13-17, 
Elsevier Scientific Publishing Company, Paris, France, May 1982.

[14] C. Xin, F. Du, K. Wang et al., "Damage evolution analysis and gas-solid coupling model for coal containing gas," Geomechanics and Geophysics for Geo-Energy and Geo-Resources, vol. 7, p. 7, 2021.

[15] M. Qian, P. Shi, and J. Xu, Mine Pressure and Strata Control, China University of mining and Technology Press, Xuzhou, China, 2010.

[16] Z. Song, Practical Mine Pressure and Control, China University of mining and Technology Press, Xuzhou, China, 1988.

[17] J. Xu and M. Qian, "Application of mining fracture distribution in green mining," Journal of China University of Mining and Technology, vol. 02, pp. 17-20, 2004.

[18] X. Zhao, J. Jiang, and B. Lan, "An integrated method to calculate the spatial distribution of overburden strata failure in longwall mines by coupling GIS and FLAC3D," International Journal of Mining Science and Technology, vol. 25, no. 3, pp. 369-373, 2015.

[19] B. Song, L. Chen, F. Zhang et al., "Study on the evolution law of the fracture influenced by mining based on fractal theory," Geotechnical Investigation \& Surveying, vol. 45, no. 1, pp. 1-6, 2017.

[20] X. Xu, N. Zhang, and S. Tian, "Mining-induced movement properties and fissure time-space evolution law in overlying strata," International Journal of Mining Science and Technology, vol. 22, no. 6, pp. 817-820, 2012.

[21] L. Yuan, H. Guo, B. Shen et al., "Circular overlying zone at longwall panel for efficient methane capture of multiple coal seams with low permeability," Journal of China Coal Society, vol. 36, no. 3, pp. 357-365, 2011.

[22] H. B. Wang, T. Li, Q. L. Zou, Z. H. Cheng, and Z. K. Yang, "Influences of path control effects on characteristics of gas migration in a coal reservoirfluences of path control effects on characteristics of gas migration in a coal reservoir," Fuel, vol. 267, Article ID 117212, 2020.

[23] D. Yang, W. Guo, Yi Tan et al., "Study on the evolution characteristics of two-zone failure mode of the overlying strata under shallow buried thick seam mining," Advances in Civil Engineering, vol. 2019, Article ID 9874769, 9 pages, 2019.

[24] W. Wang, S. Wang, H. Liu et al., "Spatial and temporal characteristics of stress recovery in fractured overlying rock mass after mining," Journal of Mining \& Safety Engineering, vol. 34, no. 1, pp. 127-133, 2017.

[25] Z. Cheng, S. Su, and X. Wang, "Study on mining-induced fracture field of contiguous coal seam with BBM-DEM simulation," Coal Science and Technology, vol. 47, no. 12, pp. 1-9, 2019.

[26] Z. Cheng, Q. Qi, H. Li et al., "Evolution of the superimposed mining induced stress-fissure field under extracting of close distance coal seam group," Journal of China Coal Society, vol. 41, no. 2, pp. 367-375, 2016.

[27] B. Zhang, H. Sun, Y. Liang et al., "Characterization and quantification of mining-induced fractures in overlying strata: implications for coalbed methane drainage," Natural Resources Research, vol. 29, 2019.

[28] W. Wang, S. Wang, H. Liu et al., "The space and time characteristics of the cover stress re-establishment of the fractured rock mass in the goaf after coal mining," Journal of Mining \& Safety Engineering, vol. 34, no. 01, pp. 127-133, 2017. 